\title{
REPENSAR A JUSTIÇA SOCIAL
}

\author{
DUBET, François. \\ Repensar la justicia social: contra el mito \\ de la igualdad de oportunidades. \\ Buenos Aires: Siglo XXI, 2011. 127 p.
}

POR

Rodrigo Manoel Dias da Silva ${ }^{1}$

\begin{abstract}
A justiça social é um dos temas mais desafiadores e instigantes do pensamento social e sociológico contemporâneo. François Dubet, renomado sociólogo francês, é um dos destacados intelectuais que tem procurado contribuir sistematicamente neste debate, sobretudo por seu interesse em compreender as dinâmicas sociais que têm favorecido a multiplicação dos registros de desigualdades sociais (DUBET, 2003), assim como em analisar os processos de exclusão e de injustiça social nos contextos escolares e nas culturas juvenis urbanas (DUBET, 2008).
\end{abstract}

"Repensar la justicia social" (DUBET, 2011)2 constitui uma obra de sistematização do estado atual das discussões acadêmicas e dos estudos teóricos sobre a justiça social. Neste sentido, o livro procura estabelecer um quadro analítico e comparativo entre duas grandes concepções de justiça social presentes no pensamento contemporâneo, quais sejam: a igualdade de posições (posicional ou de lugares) e a igualdade de oportunidades. Segundo Dubet, ambas almejam reduzir as tensões e as contradições próprias das sociedades democráticas

\footnotetext{
${ }^{1}$ Doutor em Ciências Sociais pela Universidade do Vale do Rio dos Sinos e Professor de Sociologia na UFFS, campus de Erechim. E-mail para contato: rodrigoddsilva@hotmail.com.

${ }^{2}$ Originalmente publicada na França, sob o título "Les places et les chances - Repenser la justice social” (DUBET, 2010).
} 
situadas entre a igualdade universal e as desigualdades capitalistas. De certo modo, a ênfase das duas concepções consiste em tornar as desigualdades aceitáveis, mesmo que, ao mesmo tempo, sejam diferentes e antagônicas entre si. o livro situa-se neste campo de problematizações e foi organizado em cinco capítulos.

No primeiro capítulo, o sociólogo francês explicita as principais características históricas e sociológicas da igualdade de posições. 0 contexto histórico próprio da Revolução Francesa e suas afirmações da igualdade e da liberdade de todos os homens inaugura uma contradição que se estendeu por todo 0 pensamento social no Ocidente. Tal revolução, associada à Revolução Industrial e à Científica, oportunizou a aceleração de processos de mudança social, política e econômica erigidas sob a égide do Capitalismo; porém esta ideologia do progresso material trouxe severas consequências, pois não foi por acaso que o século XIX ficou conhecido como o século da miséria operária e urbana. Os tensionamentos entre capital e trabalho, com 0 advento dos movimentos operários e sindicais, favoreceram a conquista de alguns direitos aos novos (e milhares) trabalhadores urbanos, construindo, nos termos de Robert Castel (2003), uma "sociedade salarial" capaz de enfrentar a "questão social". Os direitos sociais tornar-se-iam um instrumento capaz de assegurar uma vida digna àqueles que ocupassem uma posição social menos favorecida.

Este argumento não só auxilia na compreensão de uma determinada representação da vida em sociedade, como também traz em si um modelo de justiça social. Este modelo inspirou-se "nas ambições socialistas e nas utopias comunistas" (DUBET, 2011, p. 18, tradução do autor ${ }^{3}$ ), prioritariamente imbuído na redução das desigualdades entre as posições sociais. Nos países europeus, 0 modelo desencadeou um Estado de Bem Estar Social relativamente forte, cujo principal instrumento de intervenção política foi a redistribuição econômica. $\mathrm{Ou}$ seja, não podemos deduzir que este modelo de justiça social configurou-se apenas como filosofia abstrata ou como uma ordem moral. Ele tem representado um conjunto de escolhas políticas e de práticas sociais. Assim, não se,

[...] impediu que a igualdade de posições tenha sido promovida (e siga sendo amplamente apoiada) por atores individuais e coletivos que tenham convertido a luta de classes em compromissos sociais e em regras de direito. Criou-se um mecanismo que transforma os conflitos

\footnotetext{
${ }^{3}$ Todas as traduções deste livro, presentes nesta resenha, foram realizadas pelo autor.
} 
sociais em participação política, em redução de desigualdades e em integração social (DUBET, 2011, p. 22).

Esta ideia de justiça orienta-se pela redução das diferenças entre as posições sociais, tanto no que concerne à proteção dos atores através de garantias salariais, como pela consolidação de direitos à educação, à saúde, à habitação, à aposentadoria, etc. Nestes termos, Dubet nos esclarece que a justiça posicional decorre dos conflitos entre capital e trabalho típicos do mundo moderno, os quais compuseram a agenda histórica dos movimentos operários e dos partidos políticos da esquerda. Sendo assim, posteriormente, este modelo representou a garantia de serviços estatais em "um contrato de solidariedade ampliado" (DUBET, 2011, p. 25), onde a igualdade de acesso à escola republicana tornou-se um exemplo emblemático. A escola republicana buscava assegurar condições escolares que reduzissem as diferenças entre as posições, entretanto "sem alterar a estrutura social e suas hierarquias" (DUBET, 2011, p. 27). Podemos observar outra contradição deste modelo de justiça social quando pensamos na situação social das mulheres nos últimos dois séculos. As mulheres obtiveram diversos avanços no plano da garantia de direitos relacionados ao trabalho, porém permaneceram por muito tempo definidas como sujeito em um mundo masculino que as subalternizam. Mais do que isso, para Dubet, "o atraso das mulheres em matéria de igualdade expõe a tensão interna na igualdade de posições entre a lógica da igualdade e a lógica da seguridade social" (DUBET, 2011, p. 28). No limite desta argumentação sociológica, não podemos confundir igualdade e seguridade social.

No segundo capítulo, François Dubet procura indicar e analisar as críticas à igualdade de posições. 0 autor parte do princípio, já exposto em elaboração anterior (DUBET, 2003), de que as ambições políticas dos programas governamentais podem omitir vícios ou mesmo a ausência de percepção de que as desigualdades não são estáveis ou fixas, mas se multiplicam.

0 modelo redistributivo que organiza os princípios da igualdade de posições apresenta diversos limites. As sociedades que conseguiram organizar Estados de Bem Estar relativamente fortes são globalmente menos afetadas por processos de desigualdade, porém países onde isso não se deu da mesma maneira, vide 0 caso francês, $o$ Estado tornou-se conservador ou corporativo. Isso significa que as disputas por direitos de redistribuição (ou de cidadania) ficam dispersas em uma miríade de disputas e apostas políticas setorizadas. "Por detrás da igualdade de posições se ergue a coalizão dos regimes especiais e de corporativismos [...]", onde "nem todos são privilegiados, mas este mosaico de 
estatutos particulares parece intocável" (DUBET, 2011, p. 34-35). Neste aspecto, é como se a "questão social" caracterizada por Castel (2003) se fragmentasse em múltiplas pequenas questões atinentes a coletivos específicos (médicos, professores, operários, camponeses, etc.).

Não obstante, diversos diagnósticos científicos sobre estas questões reiteram apontamentos ponderados sobre o poder aquisitivo e de consumo da população, sobretudo das classes médias; entretanto, os mesmos não mensuram as "desigualdades novas" e a acumulação de "desigualdades minúsculas" (DUBET, 2011, p. 37). Dubet pretende destacar que nas margens da igualdade posicional estão situados grupos considerados minoritários ou socialmente discriminados, caso de regiões ou territórios desfavorecidos, diferenças geracionais, grupos etários, grupos étnicos, etc. Tais margens se explicitam nos programas de massificação escolar, quando estes expõem as fragilidades da coesão social, e nas políticas de inserção das mulheres nos mercados formais de trabalho, pois este fenômeno oportunizou diversas análises críticas acerca do acesso enquanto política exclusiva de democratização.

Segundo Dubet, uma última circunstância analítica que revela os limites da justiça posicional diz respeito aos imigrantes. Os Estados nacionais, desde 0 fim do século XVIII, foram construídos sob uma dinâmica homogeneizadora capaz de fabricar uma identidade nacional. Porém, os "franceses", enquanto representação, cada vez mais são árabes, negros, africanos ou americanos, pois "as sociedades nacionais se tornaram pluriculturais" (DUBET, 2011, p. 50). Esse fato fez emergir disputas por reconhecimento, dado que "nenhum cidadão pode ser privado de sua cultura e de sua identidade" (DUBET, 2011, p. 50). Portanto, a crítica estabelecida pelo autor à igualdade de lugares não se refere aos seus princípios e valores, mas a suas práticas e consequências.

No terceiro capítulo, o sociólogo francês trata das características da igualdade de oportunidades. Se, por um lado, atribuiu a gênese da igualdade posicional aos tensionamentos entre capital e trabalho produzidos desde a Modernidade, por outro, confere à igualdade de oportunidades um nascimento igualmente nobre no contexto da destruição do Antigo Regime e da emergência dos valores iluministas, na França. Neste aspecto, potencializou-se historicamente enquanto alternativa para o enfrentamento das desigualdades capitalistas. Hoje, tal perspectiva tem sido reivindicada pela esquerda e pela direita, tanto quanto está no cerne das principais teorias da justiça, desde John Rawls. 
A igualdade de oportunidades repousa sobre uma fiçãa e sobre um modelo estatístico que supõe que, em cada geração, os indivíduos são distribuídos de maneira proporcional em todos os níveis da estrutura social independentemente de suas origens e de suas condições iniciais (DUBET, 2011, p. 54).

Este modelo anula as heranças socioculturais $\mathrm{e}$ as diferenças de escolarização enquanto variáveis heurísticas, pois se interessa em enfatizar 0 mérito dos indivíduos, pressupondo que este produza desigualdades mais justas. A igualdade de oportunidades tem sido privilegiada na construção lógica e argumentativa das políticas contemporâneas, com ênfase em sua preocupação com aqueles agrupamentos não representados ou sub-representados nas reivindicações por direitos e cidadania. A equiparação de situações discriminatórias, as políticas de cotas e as medidas jurídicas protetivas são instrumentos utilizados para a produção de justiça social.

Os argumentos a favor da igualdade de oportunidades são contraposições à igualdade posicional. Primeiramente, o escopo argumentativo da lógica das oportunidades revela os limites e debilidades da outra lógica, evidenciando que diversos grupos não foram atingidos pela redistribuição estatal clássica. Ao mesmo tempo, modifica as representações da própria sociedade, tendo em vista que diversos grupos e atores antes "invisíveis" e "silenciados" agora demandam representação política e novos contratos sociais. Ou, ainda, que o modelo das oportunidades se impõe quando as posições se tornam escassas (DUBET, 2011). Do ponto de vista da designação dos atores na construção das políticas, os operários são tidos como classes desfavorecidas, assim como os bairros populares passam a ser denominados como bairros desfavorecidos.

Assim, a definição das posições sociais é dada em termos de oportunidades. Esta representação assume uma definição particular de justiça social operante no âmbito da luta contra discriminações, tal como uma "exigência de reconhecimento" (DUBET, 2011, p. 60). Em termos propriamente sociológicos, a categoria classe social é substituída pelo termo minoria. Deste modo, as políticas sociais deixam de ser universais e tornam-se políticas dirigidas ou focalizadas, mediante a representação de uma disputa individualizada pelo atendimento de demandas particularizadas, ou seja, almeja-se, tal como numa competição desportiva, a equidade nos pontos de partida, uma vez que a competição em si depende do mérito do concorrente. 
No quarto capítulo, por sua vez, François Dubet expõe suas críticas à igualdade de oportunidades. A partir da constatação da intensificação dos processos de desigualdade social, 0 autor evidencia que 0 argumento que subjaz a tal igualdade diz respeito a seu olhar dirigido às camadas economicamente mais favorecidas. As elites são o parâmetro em uma sociedade das oportunidades.

Em outra linha de raciocínio, podemos considerar que, nesta lógica de justiça, as disputas sociais se deslocam da relação exploração/trabalho para discriminação/identidade (DUBET, 2011). Deste modo,

Conceber as desigualdades em termos de discriminações conduz a hierarquizar as vítimas que tem interesse em exibir seus sofrimentos e as injustiças que sofrem, com a finalidade de obter a vantagem diferencial que lhes permitirá beneficiar-se com ajudas específicas. 0 mundo das vítimas, de outro lado, não é necessariamente fraternal: cada, indivíduo ou grupo, deve apresentar-se como se fosse mais vítima que os demais (DUBET, 2011, p. 77).

Este fenômeno conduz, pois, a uma competição entre os atores vitimizados por alguma condição socialmente desfavorável. Num jogo movediço e individualizado de identificações, tal como narrado por Stuart Hall (2006), cada indivíduo deve mobilizar uma produção identitária diante de um repertório denso e plural. Mesmo em sociedades multi ou pluriculturais, não deixam de crescer movimentos de afirmação identitária, sobretudo em suas dimensões fragilizadas e desprotegidas da intervenção estatal. Isso significa que a vitimização de alguns grupos culturais deriva de dinâmicas de reconhecimento cultural, entretanto 0 reconhecimento em questão desalinha-se da orientação de representativos especialistas nesta discussão, caso de Axel Honneth ${ }^{4}$.

Em síntese,

Como a igualdade de posições, a igualdade de oportunidades não é perfeita. Substitui identidades e coalizões de interesses por outras que são igualmente rígidas. Em última instância, aceita mais desigualdades que o modelo das posições, ainda que não sejam necessariamente as mesmas. De maneira mais fundamental, se apoia sobre um dos

\footnotetext{
${ }^{4}$ Neste particular, Dubet afirma que o reconhecimento é fundamental para a formação do sujeito, porém não chega a constituir, em Honneth, pelo menos, uma teoria da justiça.
} 
princípios de justiça mais frágeis e mais discutíveis: o mérito (DUBET, 2011, p. 92).

No quinto capítulo, o sociólogo recoloca o quadro comparativo entre os dois modelos de justiça social e assume um ponto de vista analítico favorável à igualdade de posições. 0 autor sustenta sua posição ao mencionar que este modelo de justiça social é mais favorável aos mais fracos e que, para 0 enfrentamento destas questões sociais, faz-se necessário perceber o quanto as desigualdades degradam a vida coletiva. Assim, a multiplicação das desigualdades sociais tem comprometido os processos democráticos contemporâneos.

Porém, Dubet enfatiza que outro seria o argumento mais potente a favor da igualdade posicional. Quanto mais forem reduzidas as desigualdades entre as posições, maior será a efetividade da lógica das oportunidades, tendo em vista que as distâncias entre as posições se tornam menores (DUBET, 2011, p. 99). Observa, então, uma relação de anterioridade, ao considerar que as oportunidades seriam mais viáveis em uma sociedade mais igualitária.

Ainda em um exercício comparativo, diz 0 autor:

A igualdade de posições me parece assim um projeto mais sólido $\mathrm{e}$ mais generoso que a igualdade de possibilidades. É mais sólido porque induz a um contrato social mais aberto, em condições de observar com maior atenção as políticas salariais, de proteção e de transferências sociais. 0 modelo de igualdade de oportunidades parece dizer sempre, ao final, que os mais favorecidos nada devem aos demais e que são livres de qualquer dívida. Mas se esquece que muito que as oportunidades individuais se beneficiam das inversões coletivas (DUBET, 2011, p. 114).

E conclui o argumento: "A justiça das posições é mais generosa porque não permite que esqueçamos o que devemos aos outros; recorda que a produção dos vencedores não exige o sacrifício dos vencidos.” (DUBET, 2011, p. 114).

0 autor conclui que ambos os modelos de justiça social podem ser desejáveis, porém faz-se necessário elencar prioridades e compreender as representações de vida social que lhes são subjacentes. Dubet aposta na igualdade posicional, ainda que de modo relativo, pois este modelo parece consolidar um sistema de direitos, obrigações e garantias sociais estendidos a toda a população. 
Ao mesmo tempo, o referido modelo favorece, a posteriori, a igualdade de oportunidades, tal como anteriormente descrito, uma vez que visa reduzir as distâncias entre as posições.

Em sua conclusão, na condição de intelectual socialmente comprometido, Dubet sugere que a igualdade posicional poderia constituir um dos novos elementos para uma reconstrução ideológica da esquerda, se esta tiver coragem de enfrentar seus fantasmas e encontrar-se com outras representações políticas da vida social.

Por fim, entendemos que esta obra constitui um importante marco analítico para a investigação dos processos de justiça e de injustiça social, tanto quanto para estudos mais aprofundados sobre os modelos de justiça que alicerçam as ações do Estado e as diversas políticas sociais de nosso tempo.

\section{REFERÊNCIAS}

CASTEL, Robert. As metamorfoses da questão social: uma crônica do salário. 4. ed. Petrópolis: Vozes, 2003.

DUBET, François. As desigualdades multiplicadas. Ijuí: Ed. Unijuí, 2003.

DUBET, François. O que é uma escola justa? São Paulo: Cortez, 2008.

DUBET, François. Les places et les chances. Repenser la justice sociale. Paris: Éditions Du Seuil et La République des Idées, 2010.

DUBET, François. Repensar la justicia social: contra el mito de la igualdade de oportunidades. Buenos Aires: Siglo XXI, 2011.

HALL, Stuart. A identidade cultural na pós-modernidade. 11. ed. Rio de Janeiro: DP\&A, 2006. 